\title{
Laboratory Environmental Conditions Influence Patent Inventors' Creative Self-efficacy
}

\author{
Shih-Hao Wang ${ }^{1}$, Chung-Lin Tsai ${ }^{2}$, Han-Chao Chang ${ }^{3}$ \\ ${ }^{1}$ Department of Management Information System, Far East University, Taiwan \\ ${ }^{2}$ Bachelor's Degree Program in Management, Chang Jung Christian University, Taiwan \\ ${ }^{3}$ Instrument Technology Research Center, National Applied Research Laboratories, Taiwan \\ Correspondence: Han-Chao Chang, No.20, R\&D Rd.VI, Hsinchu Science Park, HsinChu, Taiwan.
}

Received: March 12, 2018

Accepted: April 18, $2018 \quad$ Online Published: April 23, 2018

doi:10.5539/ibr.v11n5p159

URL: https://doi.org/10.5539/ibr.v11n5p159

\begin{abstract}
A comfortable experimental environment usually enables stress relief among inventors, allowing them to focus on inventing. However, to facilitate smooth and continuous experimental procedures, the public spaces and computing environments of conventional laboratories are usually replete with heavy instruments and interconnected wires; consequently, inventors have limited space to conduct complex experiments. These public spaces and computing environments negatively affect the creative self-efficacy (CSE) of inventors. Based on CSE theory and modified information layout complexity theory, in this study, 100 inventors who had obtained patents were recruited. The results indicated that a wireless cloud public space and computing environment positively moderated and enhanced the relationship between low layout complexity and inventor CSE; conventional public spaces and computing environments featuring cables negatively moderated and weakened the relationship between high layout complexity and inventor CSE. More than $40 \%$ of participants highly supported using one electronic tablet to manipulate multiple instruments. The results also revealed that approximately $64 \%$ of participants did not think they were essential in promoting critical mass in the laboratory. This finding was significantly different from the degree centrality of creativity perspective. Critical indicators of inventor CSE were found to be inventors' decision-making capabilities regarding innovative research directions and their communication skills with supervisors.
\end{abstract}

Keywords: public spaces and computing, creative self-efficacy (CSE), patent inventor

\section{Introduction}

Creative self-efficacy (CSE) is an individual's evaluation of their innovation ability. It regulates the individual's choice of behaviour and their efforts and ultimately determines their performance in specific tasks (Tierney \& Farmer, 2011). Particularly, for a laboratory researcher, CSE can be considered as the belief in their ability to develop creative ideas and patents (Song, Kim, \& Lee, 2017). Recent developments in wireless communication technology have reduced interference from conventional communication lines in the researchers' R\&D environment. Therefore, this study attempted to determine whether the wireless communication layout or environment can exert more positive influences on patent inventors' CSE than the environment with conventional heavy instruments and wired devices in regular science and engineering laboratories.

\section{Environmental Conditions in Regular Scientific Laboratories}

Connections through wires are required for computers in research organisations and excessive numbers of instruments in almost all regular laboratories. Many instruments for experimentation must be connected to physical computers through conventional cables; however, most light and simple mobile devices do not contain ports that support these connections. In addition to insufficient space, the layout of laboratories (Barros, 2015) poses significant risks regarding instrument or computer damage resulting from researchers accidentally falling over instruments and pulling wires while conducting experiments related to patented inventions. Moreover, public spaces and computing arrangements can interrupt researchers' creative thought processes (Thundiyil, Chiaburu, Li, \& Wagner, 2016). Regarding software, instruments, and computers, regular laboratories are equipped with certain professional (e.g., LabVIEW, Linux, Sun Solaris, and Windows 10) and self-developed operating systems. These systems require educational researchers to possess professional IT skills (Yang \& 
Cheng, 2009) and spend considerable processing time on nonexperimental data and file conversions. Therefore, because of the popularity of smart mobile devices, this study explored the feasibility of replacing conventional experimentation instruments with light and portable smart devices to alleviate space restrictions in laboratories. Based on wireless mobile devices, this study also aimed to use connectionless devices to increase researchers' CSE.

\section{Literature Review and Hypotheses}

Tullis (1983) defined 'layout complexity' as the on-screen layout of informational items that are visually recognised. Layout complexity is best reduced by arranging information into columns containing information units. After analysing 600 information screens, Tullis (1983) revealed that the average information density of such screens was approximately $25 \%$. On-screen information involving densities more than $40 \%-50 \%$ was rare. Helander et al. (1998) contended that when information density is increased, the time spent searching for data and the error rate also increase, thereby leading to considerable reductions in reading efficiency.

Bandura (1997) defined self-efficacy as 'people's beliefs about their capabilities to produce designated levels of performance that exercise influence over events that affect their lives'. Schwarzer (2001) and Wilski and Tasiemski (2017) have emphasised that a low sense of self-efficacy may induce depression, helplessness, and anxiety. Chen et al. (2001) stated that self-efficacy denotes people's beliefs in their abilities within an organisation. Chong and Ma (2010) asserted that confidence in staff self-efficacy is a vital cognitive and social trait that determines and maintains positive work performance. Subsequently, Tierney and Farmer (2011) developed a specific concept of self-efficacy to judge following capacities within the context of CSE. They indicated that CSE differs from creativity; creativity is the generation of technologically innovative and entity results in a certain field. By contrast, CSE is the belief that staff members have the ability to achieve creative outcomes in jobs. Regarding CSE, Leonard-Barton (1995) stated that when businesses operate in dynamic and changeable environments, employees must have the self-efficacy to learn from these environments and be able to create and distribute this learning throughout the organisation. Furthermore, Karwowski (2012) emphasised that CSE is significantly predicted by creative abilities. Yang and Cheng (2009) and Rohatgi et al. (2016) have posited that CSE may provide efficacy that enhances creative behaviours, and they further described that individual IT skills and the degree centrality of creativity are critical factors that influence CSE. Thundiyil et al. (2016) revealed that CSE has a positive influence on creative performance during situations of low positive affect. In our study, it was hypothesised that decision-making capabilities (Kim, Hong, Kwon, \& Lee, 2017; Leng \& Jiang, 2016) regarding the direction of prospective studies and adequate communication capabilities (Franchino \& Buttazzo, 2017; Jawhar, Mohamed, Al-Jaroodi, Agrawal, \& Zhang, 2017) between researchers and team leaders in the laboratory influence the CSE of laboratory staff.

By combining the modified information layout complexity theory (Tullis, 1983), which states that arranging information according to fields reduces layout complexity (Barros, 2015), and CSE theory (Yang \& Cheng, 2009), it can be inferred that laboratories, a public space, are similar to large computer screens that contain boundaries. When instruments are arranged in columns and the data are properly formatted on screens, the following hypotheses can be made:

- H1: High instrument layout complexity (HILC) and CSE are positively correlated.

- H2: Low instrument layout complexity (LILC) and CSE are positively correlated.

- H3: The traditional cable experimentation environment (TCEE) negatively moderates and weakens the relationship between LILC and CSE.

- H4: The TCEE negatively moderates and weakens the relationship between HILC and CSE.

- H5: The wireless cloud experimentation environment (WCEE) positively moderates and enhances the relationship between LILC and CSE;

- H6: This environment also positively moderates and enhances the relationship between HILC and CSE.

\section{Methods of Statistical Analysis}

This study employed a cross-sectional, descriptive, and inferential design. To assess content validity, five experts specialising in public spaces (Hohberger, Almeida, \& Parada, 2015) and computing and the human-computer interface (Nandakumar \& Funk, 2015) aided in the completion of the study and scored the initial questionnaire. Purposive sampling techniques were used to recruit inventors. When inventors who had obtained patents in the laboratories under study agreed to complete the questionnaire, it was emailed to them. Frequent follow-up calls were conducted when the questionnaire was not returned within 1 week after being emailed. The questionnaire 
contained items regarding the aforementioned variables. A 5-point Likert scale was used to evaluate inventors' responses to this survey $(1=$ strongly disagree, $2=$ disagree, $3=$ acceptable, $4=$ agree, $5=$ strongly agree $)$. In total, 120 surveys were distributed, and 110 questionnaires were returned, achieving a response rate of $91.7 \%$. After adjusting for nonvalid responses $(n=10), 100$ questionnaires were analysed.

The analysis framework is provided in Figure 1. To test the specific hypotheses, reliability analysis, Pearson's correlation analysis (Ar \& Bostanci, 2016), and moderated hierarchical regression analysis (MHRA; Ekrot, Rank, $\&$ Gemünden, 2016) were performed. Cronbach's $\alpha$ was used to measure reliability and inner consistency within each dimension. According to the suggestions of Eisinga (2013), a Cronbach's $\alpha$ value between 0.7 and 0.98 indicates high reliability; a Cronbach's $\alpha$ value above 0.6 indicates that reliability is acceptable in exploratory research.

Pearson's correlation analysis was used to explore the relationship between the two ILCs (high and low) and dependent variables (DVs; i.e., CSE). MHRA was conducted to predict the relationships between independent variables (IVs) and the relationship between each IV and a specific corresponding DV.

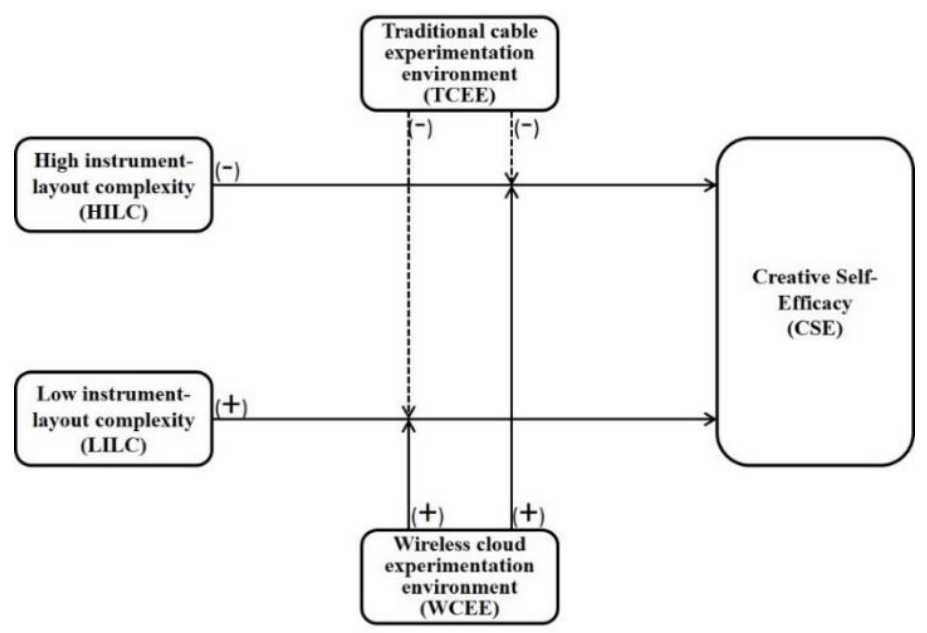

Figure 1. Study framework

In addition, MHRA was used to determine the main effects of the ILC on CSE and to independently assess how the conventional wired environment and cloud computing environment moderate the relationship between ILC and CSE. In Step 1, the two ILC variables (high and low) were added as a set in SPSS 16.0 software. In Step 2, the environments (wired and cloud) were entered SPSS to analyse any effects of the ILC on CSE or the relationship between the two variables. Finally, in Step 3, the cross-products of each of the environments and CSE were entered as a set in SPSS software. Evidence of moderation exists when a set of interacting variables account for significant residual variances in the DV (Youndt, Snell, Dean Jr., \& Lepak, 1996). Significant effects indicate that the environment moderates the relationship between ILC and CSE, thereby supporting the proposed hypotheses. Individual interacting variables (e.g., TCEE by HILC) were used to test specific moderating hypotheses. Support for these hypotheses was confirmed if the individual IVs accounted for significant residual variances in the operational performance.

\section{Discussion and Statistical Results}

In reliability analysis, scores ranged from .62 to .78 (Table 1), thereby indicating the acceptable internal consistency of all dimensions, and that the items addressed the properties of the research variables. Pearson's correlation analysis was conducted to examine trends in the data. The following key variables were included in this analysis: HILC, LILC, and CSE. As shown in Table 2, the results revealed that the correlation was significant at the .01 level $(p<.01)$; therefore, CSE was positively associated with HILC, and the correlation was significant at the 0.01 level $(p<0.01)$; CSE was also positively associated with LILC, thereby supporting H1 and $\mathrm{H} 2$. 
Table 1. Items and reliability of each variable $(\mathrm{N}=100)$

\begin{tabular}{|c|c|c|}
\hline Dimensions & Items & $\begin{array}{c}\text { Average } \\
\text { Cronbach } \alpha\end{array}$ \\
\hline $\begin{array}{l}\text { HILC } \\
(4)\end{array}$ & $\begin{array}{l}\text { 1. Do you like conducting experiments in laboratories where instruments are } \\
\text { arranged randomly and not according to size? } \\
\text { 2. Do you like conducting lectures in laboratories where instruments are arranged } \\
\text { randomly and not according to type? } \\
\text { 3. Do you like conducting lectures in laboratories where the space between } \\
\text { instrument cabinets is unsuitable? } \\
\text { 4. Do you like conducting experiments in laboratories filled with miscellaneous } \\
\text { equipment? }\end{array}$ & 0.74 \\
\hline $\begin{array}{l}\text { LILC } \\
(4)\end{array}$ & $\begin{array}{l}\text { 1. Do you like conducting experiments in laboratories where instruments are } \\
\text { arranged according to size? } \\
\text { 2. Do you like conducting lectures in laboratories where instruments are arranged } \\
\text { according to type? } \\
\text { 3. Do you like conducting lectures in laboratories where the space between } \\
\text { instrument cabinets is suitable? } \\
\text { 4. Do you like conducting experiments in laboratories not filled with miscellaneous } \\
\text { equipment? }\end{array}$ & 0.78 \\
\hline $\begin{array}{l}\text { CSE } \\
(4)\end{array}$ & $\begin{array}{l}\text { 1. You have gained experience from external environments and increased your } \\
\text { innovativeness based on this experience. } \\
\text { 2. You are proficient in manipulating multiple professional operating systems. } \\
\text { 3. You are essential in the laboratory and prompt critical mass. } \\
\text { 4. You have strong communication skills when discussing experiments with your } \\
\text { laboratory supervisor. } \\
\text { 5. You possess high decision-making abilities regarding the innovative research } \\
\text { directions in your laboratory. }\end{array}$ & 0.62 \\
\hline $\begin{array}{l}\text { TCEE } \\
(4)\end{array}$ & $\begin{array}{l}\text { 1. You like conducting experiments in laboratories that provide limited space. } \\
\text { 2. You like conducting experiments in laboratories where the wires of instruments are } \\
\text { intertwined. } \\
\text { 3. You like conducting experiments in laboratories where all instruments have } \\
\text { separate professional operating systems. } \\
\text { 4. You believe that the traditional cable experimentation environment facilitates } \\
\text { teamwork. }\end{array}$ & 0.75 \\
\hline $\begin{array}{l}\text { WCEE } \\
\text { (4) }\end{array}$ & $\begin{array}{l}\text { 1. You like conducting experiments in laboratories where wires are not intertwined. } \\
\text { 2. You like cloud computing, which integrates the experimental results obtained from } \\
\text { all instruments. } \\
\text { 3. You like conducting experiments in laboratories where one electronic tablet } \\
\text { controls multiple instruments for teaching. } \\
\text { 4. You believe that the wireless cloud experimentation environment facilitates } \\
\text { teamwork. }\end{array}$ & 0.67 \\
\hline
\end{tabular}


Table 2. Pearson's Correlations

\begin{tabular}{llccc}
\hline & & HI_Ave & LI_Ave & CSE_Ave \\
\hline HI_Ave & Pearson's correlation & 1 & $.578^{* *}$ & $.539^{* *}$ \\
& Sig. (two-tailed) & & .000 & .000 \\
& Sum of squares and Cross-products & 51.215 & 28.658 & 19.702 \\
& Covariance & .517 & .289 & .199 \\
LI_Ave & $\mathrm{N}$ & 100 & 100 & 100 \\
& Pearson's correlation & $.578^{* *}$ & 1 & $.638^{* *}$ \\
& Sig. (two-tailed) & .000 & & .000 \\
& Sum of squares and Cross-products & 28.658 & 47.932 & 22.554 \\
& Covariance & .289 & .484 & .228 \\
& $\mathrm{~N}$ & 100 & 100 & 100 \\
\hline
\end{tabular}

**. Correlation is significant at the 0.01 level (two-tailed).

*. Correlation is significant at the 0.05 level (two-tailed).

When the relationships between CSE and HILC and LILC were examined, significant differences were observed: $\mathrm{p}<.001,45.1 \%, \mathrm{R} 2=0.451, \Delta \mathrm{R} 2=0.451, \mathrm{~F}=39.814$, and the data fit appropriately well with Model 1 (Table 3). In addition, the coefficients for both IVs (i.e., HILC: $\beta=0.256, t=2.773, p=.007$; LILC: $\beta=0.490, t=$ $5.315, \mathrm{p}<.001)$ fit appropriately with the model. The correlation between HILC and CSE and that between LILC and CSE in Model 1 were significant. Therefore, HILC and LILC were associated with CSE, thus supporting $\mathrm{H} 1$ and $\mathrm{H} 2$.

In the MHRA of Model 2, the IVs (i.e., HILC and LILC) and the moderating variables (i.e., TCEE and WCEE) were added sequentially as a set in the model to control for any environmental effects on ILC, CSE, or the relationship between these variables. Model 2 showed the following results: $46.5 \%$ ( $R 2=0.465, \triangle \mathrm{R} 2=0.014, \mathrm{~F}$ $=20.624, \mathrm{p}<.001$; Table 3$)$, and the level of significance was reached. The coefficient of the IV of LILC $(\beta=$ $0.509, \mathrm{t}=5.430, \mathrm{p}<.001$ ) was also significant. Therefore, the correlation between LILC and CSE in Model 2 was significant. Thus, LILC was positively associated with CSE.

Finally, in Model 3, each of the interactions between the variables related to the laboratory environment and ILC was explored. The variables (HILC, LILC, HILC $\times$ TCEE, HILC $\times$ WCEE, LILC $\times$ TCEE, and LILC $\times$ WCEE) were entered concurrently, and possible multicollinearity was controlled for. Model 3 significantly fit at $51.4 \%$ $(\mathrm{R} 2=0.514, \Delta \mathrm{R} 2=0.050, \mathrm{~F}=12.045, \mathrm{p}<.001$; Table 3$)$. The following results were obtained for the coefficients of IVs in Model 3: HILC: $\beta=2.688, t=2.783, p=.007$; HILC $\times$ WCEE: $\beta=-2.392, t=-3.015, p$ $=.003 ;$ HILC $\times$ TCEE: $\beta=-2.523, \mathrm{t}=-1.944, \mathrm{p}<.05$; LILC $\times$ WCEE: $\beta=2.898, \mathrm{t}=2.837, \mathrm{p}=.006$; and LILC $\times$ TCEE: $\beta=1.804, t=1.540$. According to the results of the MHRA of Model 3, the correlations between HILC, HILC $\times$ WCEE, HILC $\times$ TCEE, LILC $\times$ WCEE, and CSE all achieved statistical significance (Table 3). Therefore, $\mathrm{H} 4$ and $\mathrm{H} 5$ were supported. The TCEE negatively moderated and weakened the relationship between HILC and CSE (H4). The WCEE positively moderated and strengthened the relationship between LILC and CSE (H5). H3 was not supported. However, unlike H6, the WCEE did not enhance the relationship between HILC and CSE. The reasons for this should be explored in future studies.

Table 3. Results of Hierarchical Regression Analysis for CSE

\begin{tabular}{cccc}
\hline Variable & Step 1 & Step 2 & Step 3 \\
\hline HILC & $0.256^{* *}$ & 0.141 & $2.688^{* *}$ \\
LILC & $0.490^{* * *}$ & $0.509^{* * *}$ & -1.847 \\
TCEE & & 1.282 & 0.514 \\
WCEE & & 0.304 & -0.170 \\
HILC×WCEE & & & $-2.392^{* *}$ \\
HILC×TCEE & & $-2.523^{*}$ \\
LILC×WCEE & & & $2.898^{* *}$ \\
LILC×TCEE & 0.451 & 0.465 & 1.804 \\
$\mathrm{R}^{2}$ & 0.451 & 0.014 & 0.514 \\
$\Delta \mathrm{R}^{2}$ & $39.814^{* * *}$ & $20.624^{* * *}$ & 0.050 \\
$\mathrm{~F}$ & & & $12.045^{* * *}$ \\
\hline
\end{tabular}

$* * * p_{-}<.001 * * p<.01 * p<.05$

According to the statistical results of satisfaction and the mean of question CSE-03 (Table 4), 64\% of participants (given agree $(4)+$ strongly agree $(5)=64 \%$ ) believed that they were not important figures that contribute to critical mass in the laboratory. This phenomenon was significantly different from the degree 
centrality of creative perspective, which is a vital factor of CSE (Rohatgi et al., 2016; Yang \& Cheng, 2009). One possible reason for this is that participants worked in laboratories where personal charisma or research achievements were less vital in attracting fellow inventors to conduct innovative research (Alstadsæter, Barrios, Nicodeme, Skonieczna, \& Vezzani, 2018), because most research topics were assigned with patent-approval orientation by firms. This statement is justified by theoretical factors CSE-04 and CSE-05 proposed in this study. Most participants (agreement $4+5>68$ ) believed they possessed high decision-making abilities regarding innovative research directions in their laboratories and exhibited strong communication skills in discussing experiments with their laboratory supervisors (Table 4).

According to the statistical results of satisfaction and the mean of question CSE-04 (Table 4), most participants (agreement $4+5>75 \%$ ) agreed that increased IT skills enabled the use of multiple operating systems, which strengthened CSE. Regarding question CSE-02, although most participants (>75\%) agreed that using multiple operating systems increased inventors' CSE, approximately $50 \%$ of participants did not prefer or did not provide their opinions regarding conducting experiments in laboratories providing limited space and regarding every instrument being controlled by different operating systems (TCEE-01 and TCEE-03). Although participants stated that possessing professional IT skills is advantageous, not every participant preferred different operating systems at all times. Physiochemical or engineering experiments generally involve numerous steps, and inventors must manage many variables in experiments (Naqshbandi \& Kaur, 2015); therefore, they seldom have the time and energy to manage various operating systems. This attitude was reflected in WCEE-03 (Table 5), which indicated that approximately $40 \%$ of participants highly supported the concept of using one electronic tablet to control multiple instruments while lecturing.

Analysis of laboratory environmental conditions (Table 5) revealed that $48 \%$ of participants believed that the TCEE (TCEE-04, agreement $4+5=48$ ) facilitated teamwork, and only $19 \%$ believed that the WCEE (WCEE-04) enhanced teamwork (Table 5). One possible reason is that the cloud computing environment is not yet common in regular scientific laboratories; therefore, rather than personally experiencing the effectiveness of this environment, participants may be comfortable working in the conventional cable environment and may closely identify with it. This preliminary inference not only explains why participants thought that the TCEE facilitates teamwork but also why the study results (i.e., the WCEE did not enhance the relationship between HILC and CSE) differed from H6. These reasons for this result require verification.

Table 4. The Satisfactory and Mean of Each Question $(n=100)$

\begin{tabular}{lcccrcc}
\hline $\begin{array}{c}\text { No. of } \\
\text { Questionnaire }\end{array}$ & \multicolumn{5}{c}{ Agreement(low $\rightarrow$ high) } & Mean \pm SD \\
\cline { 1 - 3 } HILC-01 & $1-\mathrm{n}(\%)$ & $2-\mathrm{n}(\%)$ & $3-\mathrm{n}(\%)$ & $4-\mathrm{n}(\%)$ & $5-\mathrm{n}(\%)$ & $3.84 \pm 0.11$ \\
HILC-02 & $(2.0 \%)$ & $11(11.0 \%)$ & $24(24.0 \%)$ & $27(27.0 \%)$ & $36(36.0 \%)$ & $4.32 \pm 0.10$ \\
HILC-03 & $(2.0 \%)$ & $8(8.0 \%)$ & $0(0.0 \%)$ & $36(36.0 \%)$ & $54(54.0 \%)$ & $4.02 \pm 0.93$ \\
HILC-04 & $(0.0 \%)$ & $9(9.0 \%)$ & $15(15.0 \%)$ & $41(41.0 \%)$ & $35(35.0 \%)$ & $3.98 \pm 0.08$ \\
LILC-01 & $(0.0 \%)$ & $0(0.0 \%)$ & $33(33.0 \%)$ & $36(36.0 \%)$ & $31(31.0 \%)$ & $3.58 \pm 0.09$ \\
LILC-02 & $(0.0 \%)$ & $12(12.0 \%)$ & $32(32.0 \%)$ & $42(42.0 \%)$ & $14(14.0 \%)$ & $3.98 \pm 0.10$ \\
LILC-03 & $(0.0 \%)$ & $6(6.0 \%)$ & $30(30.0 \%)$ & $24(24.0 \%)$ & $40(40.0 \%)$ & $4.07 \pm 0.90$ \\
LILC-04 & $(0.0 \%)$ & $6(6.0 \%)$ & $19(19.0 \%)$ & $37(37.0 \%)$ & $38(38.0 \%)$ & $3.90 \pm 0.08$ \\
CSE-01 & $(0.0 \%)$ & $6(6.0 \%)$ & $21(21.0 \%)$ & $50(50.0 \%)$ & $23(23.0 \%)$ & $4.28 \pm 0.08$ \\
CSE-02 & $(0.0 \%)$ & $0(0.0 \%)$ & $18(18.0 \%)$ & $36(36.0 \%)$ & $46(46.0 \%)$ & $4.01 \pm 0.07$ \\
CSE-03 & $(0.0 \%)$ & $0(0.0 \%)$ & $25(25.0 \%)$ & $49(49.0 \%)$ & $26(26.0 \%)$ & $3.16 \pm 0.11$ \\
CSE-04 & $(0.0 \%)$ & $37(37.0 \%)$ & $27(27.0 \%)$ & $19(19.0 \%)$ & $17(17.0 \%)$ & $4.44 \pm 0.07$ \\
CSE-05 & $(0.0 \%)$ & $0(0.0 \%)$ & $9(9.0 \%)$ & $38(38.0 \%)$ & $53(53.0 \%)$ & $3.92 \pm 0.08$ \\
TCEE-01 & $(0.0 \%)$ & $0(0.0 \%)$ & $33(33.0 \%)$ & $42(42.0 \%)$ & $25(25.0 \%)$ & $3.45 \pm 0.10$ \\
TCEE-02 & $(0.0 \%)$ & $19(19.0 \%)$ & $33(33.0 \%)$ & $32(32.0 \%)$ & $16(16.0 \%)$ & $3.71 \pm 0.09$ \\
TCEE-03 & $(0.0 \%)$ & $10(10.0 \%)$ & $30(30.0 \%)$ & $39(39.0 \%)$ & $21(21.0 \%)$ & $3.49 \pm 0.11$ \\
TCEE-04 & $(0.0 \%)$ & $25(25.0 \%)$ & $28(28.0 \%)$ & $20(20.0 \%)$ & $27(27.0 \%)$ & $3.44 \pm 0.09$ \\
WCEE-01 & $(0.0 \%)$ & $16(16.0 \%)$ & $36(36.0 \%)$ & $36(36.0 \%)$ & $12(12.0 \%)$ & $3.27 \pm 0.11$ \\
WCEE-02 & $(0.0 \%)$ & $29(29.0 \%)$ & $31(31.0 \%)$ & $24(24.0 \%)$ & $16(16.0 \%)$ & $3.10 \pm 0.09$ \\
WCEE-03 & $(0.0 \%)$ & $26(26.0 \%)$ & $45(30.0 \%)$ & $22(22.0 \%)$ & $7(7.0 \%)$ & $3.24 \pm 0.11$ \\
WCEE-04 & $(0.0 \%)$ & $32(32.0 \%)$ & $28(28.0 \%)$ & $24(24.0 \%)$ & $16(16.0 \%)$ & $2.67 \pm 0.11$ \\
\hline
\end{tabular}


Table 5. Comparing the Agreement (4 + 5) for Questions on TCEE and WCEE

\begin{tabular}{|c|c|c|c|}
\hline Item No. & Items & $\%$ & $\%$ \\
\hline TCEE-02 & $\begin{array}{l}\text { You like conducting experiments in laboratories where the wires of } \\
\text { instruments are intertwined. }\end{array}$ & 60 & - \\
\hline WCEE-01 & $\begin{array}{l}\text { You like conducting experiments in laboratories where the wires of } \\
\text { are not intertwined. }\end{array}$ & - & 40 \\
\hline TCEE-03 & $\begin{array}{l}\text { You like conducting experiments in laboratories where all } \\
\text { instruments have separate professional operating systems. }\end{array}$ & 47 & - \\
\hline WCEE-02 & $\begin{array}{l}\text { You like cloud computing, which integrates the experimental results } \\
\text { obtained from all instruments. }\end{array}$ & - & 29 \\
\hline TCEE-04 & $\begin{array}{l}\text { You believe that the traditional cable experimentation environment } \\
\text { facilitates teamwork. }\end{array}$ & 48 & - \\
\hline WCEE-04 & $\begin{array}{l}\text { You believe that the wireless cloud experimentation environment } \\
\text { facilitates teamwork. }\end{array}$ & - & 19 \\
\hline
\end{tabular}

\section{Conclusion}

This study restricted analysis to inventors who are employed and have obtained patents from the Taiwan Intellectual Property Office; thus, the findings are not applicable to inventors of utility or design patents or those in other countries. Inventors in effective public spaces and computing environments tend to conduct high-quality experiments. This study used arranged information screen formatting to differentiate the complexities of laboratory instrument layouts and verified that experimentation environments containing LILC were significantly positively correlated to CSE. MHRA was conducted and revealed that the conventional experimentation environment containing intertwined instrument wires and various operating systems for equipment weakened the relationship between HILC and CSE. This study proposes that a public environment containing cloud computing and mobile devices enhances the relationship between LILC and CSE. Therefore, constructing an experimentation environment by integrating an instrument operating system and cloud computing mobile devices is a future research direction for patent inventions.

\section{References}

Alstadsæter, A., Barrios, S., Nicodeme, G., Skonieczna, A. M., \& Vezzani, A. (2018). Patent boxes design, patents location, and local R\&D. Economic Policy, 33(93), 131-177. https://doi.org/10.1093/epolic/eix021

Ar, Y., \& Bostanci, E. (2016). A genetic algorithm solution to the collaborative filtering problem. Expert Systems with Applications, 61, 122-128. https://doi.org/10.1016/j.eswa.2016.05.021

Bandura, A. (1997). Personal efficacy in psychobiologic functioning. In G. V. Caprara (Ed.), Bandura: A leader in psychology (pp. 43-66). Milan, Italy: Franco Angeli.

Barros, H. M. (2015). Exploring the use of patents in a weak institutional environment: The effects of innovation partnerships, firm ownership, and new management practices. Technovation, 45-46, 63-77. https://doi.org/10.1016/j.technovation.2015.05.003

Chen, G., Casper, W. J., \& Cortina, J. M. (2001). The roles of self-efficacy and task complexity in the relationships among cognitive ability, conscientiousness, and work-related performance: a meta-analytic examination. Human Performance, 14(3), 209-230. https://doi.org/10.1207/S15327043HUP1403_1

Chong, E., \& Ma, X. F. (2010). The influence of individual factors, supervision and work environment on creative self-efficacy. Creativity and Innovation Management, 19(3), 233-247. https://doi.org/10.1111/j.1467-8691.2010.00557.x

Eisinga, R., Grotenhuis, M. T., \& Pelzer, B. (2013). The reliability of a two-item scale: Pearson, Cronbach, or Spearman-Brown? International Journal of Public Health, 58(4), 637-642. https://doi.org/10.1007/s00038-012-0416-3

Ekrot, B., Rank, J., \& Gemünden, H. G. (2016). Antecedents of project managers' voice behavior: The moderating effect of organization-based self-esteem and affective organizational commitment. International Journal of Project Management, 34(6), 1028-1042. https://doi.org/10.1016/j.ijproman.2015.10.011

Franchino, G., \& Buttazzo, G. (2017). A power-aware MAC layer protocol for real-time communication in wireless embedded systems. Journal of Network and Computer Applications, 82, 21-34. https://doi.org/10.1016/j.jnca.2017.01.006

Helander, M. G., Landauer, T. K., \& Prabhu, P. V. (1998). Handbook of human-computer interaction ( $2^{\text {nd }}$ ed.). North-holland: Elsevier Science.

Hohberger, J., Almeida, P., \& Parada, P. (2015). The direction of firm innovation: The contrasting roles of strategic alliances and individual scientific collaborations. Research Policy, 44(8), 1473-1487. 
https://doi.org/10.1016/j.respol.2015.04.009

Jawhar, I., Mohamed, N., Al-Jaroodi, J., Agrawal, D. P., \& Zhang, S. (2017). Communication and networking of UAV-based systems: Classification and associated architectures. Journal of Network and Computer Applications, 84, 93-108. https://doi.org/10.1016/j.jnca.2017.02.008

Karwowski, M. (2012). Did curiosity kill the cat? relationship between trait curiosity, creative self-efficacy and creative personal identity. Europe's Journal of Psychology, 8(4), 547-558. https://doi.org/10.5964/ejop.v8i4.513

Kim, H. W., Hong, S. W., Kwon, O. J., \& Lee, C. Y. (2017). Concentric diversification based on technological capabilities: Link analysis of products and technologies. Technological Forecasting and Social Change, In Press. https://doi.org/10.1016/j.techfore.2017.02.025

Leng, J., \& Jiang, P. (2016). A deep learning approach for relationship extraction from interaction context in $\begin{array}{lllll}\text { social manufacturing paradigm. Knowledge-Based } & \text { Systems, } & 100,199 .\end{array}$ https://doi.org/10.1016/j.knosys.2016.03.008

Leonard-Barton, D. (1995). Wellsprings of knowledge: building and sustaining in the source of innovation. Boston, MA: Harvard Business School Press.

Nandakumar, K., \& Funk, J. L. (2015). Understanding the timing of economic feasibility: The case of input interfaces for human-computer interaction. Technology in Society, 43, 33-49. https://doi.org/10.1016/j.techsoc.2015.10.001

Naqshbandi, M. M., \& Kaur, S. (2015). Effectiveness of innovation protection mechanisms in Malaysian high-tech sector. Management Research Review, 38(9), 952-969.

https://doi.org/10.1108/MRR-01-2014-0002

Rohatgi, A., Scherer, R., \& Hatlevik, O. E. (2016). The role of ICT self-efficacy for students' ICT use and their achievement in a computer and information literacy test. Computers \& Education, 102, 103-116. https://doi.org/10.1016/j.compedu.2016.08.001

Schwarzer, R. (2001). Social-cognitive factors in changing health-related behaviors. Current Directions in Psychological Science, 10(2), 47-51. https://doi.org/10.1111/1467-8721.00112

Song, K., Kim, K. S., \& Lee, S. (2017). Discovering new technology opportunities based on patents: Text-mining and F-term analysis. Technovation, 60, 1-14. https://doi.org/10.1016/j.technovation.2017.03.001

Thundiyil, T. G., Chiaburu, D. S., Li, N., \& Wagner, D. T. (2016). Joint effects of creative self-efficacy, positive and negative affect on creative performance. Chinese Management Studies, 10(4), 726-746. https://doi.org/10.1108/CMS-06-2016-0126

Tierney, P., \& Farmer, S. M. (2011). Creative self-efficacy development and creative performance over time. Journal of Applied Psychology, 96(2), 277-293. https://doi.org/10.1037/a0020952

Tullis, T. S. (1983). The formatting of alphanumberic displays: a review and analysis. Human Factors: The Journal of the Human Factors and Ergonomics Society, 25(6), 657-682. https://doi.org/10.1177/001872088302500604

Wilski, M., \& Tasiemski, T. (2017). Meaning of Self in Multiple Sclerosis: Implications for Treatment and Rehabilitation. In A. A. A. Asea, F. Geraci, \& P. Kaur (Eds.), Multiple Sclerosis: Bench to Bedside: Global Perspectives on a Silent Killer (pp. 43-55). Cham: Springer International Publishing. https://doi.org/10.1007/978-3-319-47861-6_4

Yang, H. L., \& Cheng, H. H. (2009). Creative self-efficacy and its factors: an empirical study of information system analysts and programmers. Computers in Human Behavior, 25, 429-438. https://doi.org/10.1016/j.chb.2008.10.005

Youndt, M., Snell, S. A., Dean Jr., J. W., \& Lepak, D. P. (1996). Human resource management, manufacturing strategy, and firm performance. Academy of Management Journal, 39(4), 836-866. https://doi.org/10.2307/256714

\section{Copyrights}

Copyright for this article is retained by the author(s), with first publication rights granted to the journal.

This is an open-access article distributed under the terms and conditions of the Creative Commons Attribution license (http://creativecommons.org/licenses/by/4.0/). 